\title{
Performance of Protective Coatings for Aluminum Alloys in the Operating Conditions of Oil Production Equipment
}

\author{
Oleg Shvetsov ${ }^{1}$, Sergey Kondrat'ev ${ }^{1}$ \\ ${ }^{1}$ Peter the Great St. Petersburg Polytechnic University, 195251 Saint Petersburg, Russia
}

\begin{abstract}
The paper investigates wear resistance and corrosion resistance of protective coatings of D16 aluminum alloy under conditions that simulate operation of drill pipes. The paper also presents microstructure of coatings, electrochemical potential and corrosion rate of D16 aluminum alloy with various coatings. We evaluated adhesion and wear resistance of these coatings. D16 alloy with a tungsten carbide coating has the widest range of service properties and can be used to effectively protect the surface of aluminum drill pipes during operation operation.
\end{abstract}

\section{Introduction}

Development of oil and gas industry leads to constant complication of well drilling conditions, which requires the use of new materials for the manufacture of drill pipes and their reasonable choice for specific conditions [1-5]. Research has shown the advantages and prospects of using aluminum alloys (in comparison with steels) as a drill pipe material in the development of oil fields [610]. Despite having significant advantages, including corrosion resistance [11-12], aluminum drill pipes are inferior to steel ones in terms of wear resistance. The following methods can be used to increase the wear resistance of aluminum pipes: heat treatment, cold deformation, surface hardening, etc. [13-17]. The most economical one is the use of protective coatings for pipe metal. The coating should have necessary adhesion to the base metal and continuity, and the technology of its application should not change service properties of the substrate. As there is no information in scientific literature on the effect of protective coatings on the properties of aluminum drill pipes, the research can be considered as a topical one.

The aim of this work is to study the effectiveness of various protective coatings that can improve performance properties of aluminum alloys used for the manufacture of drill pipes.

\section{Research Material and Methodology}

For research, we used billets of drill pipes with a diameter of $147 \mathrm{~mm}$ and $126 \mathrm{~mm}$ from D $16 \mathrm{~T}$ aluminum alloy in the delivered state (hardening and natural aging). The chemical composition of the pipe material corresponds to the standard D 16 aluminum alloy (GOST 4784-97). An exception is the increased silicon content in the workpieces, which were coated with G 4 (Table 1).
Various formulations were used for the coating. We obtained coating samples from three different manufacturers. Coatings $\mathrm{P}$ and $\mathrm{K}$ were applied to a pipe billet of D16 aluminum alloy in after quenching and natural aging state, and coating $G$ was applied to the billet after annealing. All coatings were applied to an aluminum pipe by high speed flame spraying.

Table 1. Actual chemical composition of D16T alloy samples used for the deposition of various coatings.

\begin{tabular}{|c|c|c|c|c|c|c|c|c|c|c|}
\hline \multirow{2}{*}{$\begin{array}{l}\text { Alloy } \\
\text { grade }\end{array}$} & \multirow{2}{*}{$\begin{array}{l}\text { Coating } \\
\text { material }\end{array}$} & \multicolumn{9}{|c|}{ Chemical composition (wt. \%) } \\
\hline & & $\mathrm{Al}$ & $\mathrm{Mg}$ & $\mathrm{Zn}$ & $\mathrm{Mn}$ & $\mathrm{Cu}$ & $\mathrm{Cr}$ & $\mathrm{Ti}$ & $\mathrm{Fe}$ & $\mathrm{Si}$ \\
\hline \multirow{2}{*}{$\begin{array}{c}\text { D16 } \\
\text { (Base P) }\end{array}$} & P 1 & bas. & 1.59 & 0.24 & 0.49 & 4.39 & 0.02 & 0.04 & 0.23 & 0.20 \\
\hline & Р 3 & bas. & 1.50 & 0.05 & 0.67 & 4.89 & 0.01 & 0.04 & 0.44 & 0.24 \\
\hline \multirow{3}{*}{$\begin{array}{c}\text { D16 } \\
\text { (Base K) }\end{array}$} & K 1 & bas. & 1.50 & 0.15 & 0.78 & 4.79 & 0.03 & 0.06 & 0.08 & 0.06 \\
\hline & K 2 & bas. & 1.57 & 0.16 & 0.70 & 4.75 & 0.03 & 0.06 & 0.08 & 0.03 \\
\hline & K 3 & bas. & 1.57 & 0.12 & 0.75 & 4.68 & 0.01 & 0.05 & 0.06 & 0.07 \\
\hline \multirow{3}{*}{$\begin{array}{c}\text { D16 } \\
\text { (Base G) }\end{array}$} & G 1 & bas. & 1.26 & 0.14 & 0.64 & 4.71 & 0.04 & 0.09 & 0.14 & 0.08 \\
\hline & G 2 & bas. & 1.25 & 0.13 & 0.68 & 4.20 & 0.03 & 0.09 & 0.15 & 0.05 \\
\hline & G 4 & bas. & 1.32 & 0.14 & 0.73 & 4.81 & 0.03 & 0.03 & 0.05 & 1.99 \\
\hline
\end{tabular}

We used a Reichert-Jung MeF3A optical microscope at magnifications of $\mathrm{x} 100-500$ to carry out metallographic analysis of longitudinal and transverse sections of the alloy. The chemical composition of the coatings was determined with a help of a SUPRA 55 / $55 \mathrm{VP}$ field emission scanning electron microscope. Manufacture and preparation of metallographic sections was carried out on the equipment of the "Buehler" company according to ASTM E 3-95 standard.

Microhardness was determined by the Vickers method using a Reichert-Jung Micro-Duromat 4000E device in accordance with ASTM E 92 procedure.

The metal electrode potential was measured in a solution of $5 \%$ sodium chloride using three samples for each coating variant. The potential was measured using a high-resistance voltmeter using a standard silver chloride

*Corresponding author: shvec_off@mail.ru 
reference electrode having an intrinsic potential relative to a normal hydrogen electrode of $-0.200 \mathrm{~V}$. The experiment lasted for 120 hours. The electrode potentials of the samples were measured for 60 min daily.

The corrosion rate of the metal-coating pair by weight loss was determined in accordance with the requirements of ASTM G71-81 standard and was calculated in accordance with GOST 9.908-85formula:

$$
V c=(m \kappa-m 0) / S t,
$$

where Vc is a corrosion rate, $\mathrm{g} / \mathrm{m} 2 \mathrm{~h}$; $\mathrm{m \kappa}$ is a sample weight after testing, $\mathrm{g}$; $\mathrm{m} 0$ is a sample weight before testing, $\mathrm{g} ; \mathrm{S}$ is a sample surface area, $\mathrm{m} 2$; $\mathrm{t}$ is test duration, $\mathrm{h}$.

Mechanical properties of coated alloys were determined during three-point bending tests using the apparatus shown in figure 1 .

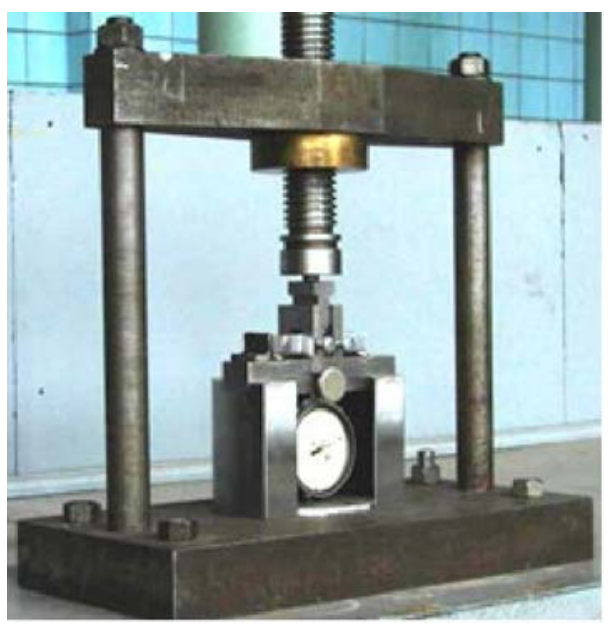

Fig 1. Apparatus that determines mechanical properties of coatings.

The calculation of stresses during testing was carried out by the finite element method with the use of Cosmos Works package (geometry of each sample was taken into account).

The test on wear resistance of coatings was carried out on a stand (Fig. 2). The stand is equipped with three motors that allows for the following simultaneous movements: to rotate the shaft with the test body at a speed of up to $150 \mathrm{rpm}$; rotate the counter body by means of a toothed gear and a chain drive at a speed of up to $50 \mathrm{rpm}$; move the test body relative to the counter body at a speed of up to $5 \mathrm{~m} / \mathrm{h}$. The test body is pressed against the counter body using a special device with a force of up to $300 \mathrm{kgf}$. Flushing fluid tank capacity is 250 liters. The liquid is supplied to the point of contact of the test body with the counter body by means of a pump, and then gravity sends it back to the tank. The control of the measured parameters (friction torque, pressing force, and shaft rotation speed), as well as control of motors that provide three types of motion (rotation and longitudinal movement of the sample, rotation of the counter body), were carried out by the control panel. The data received from the sensors are processed using the Dacell TMS Ver 1.1 software and stored in tables and graphs.

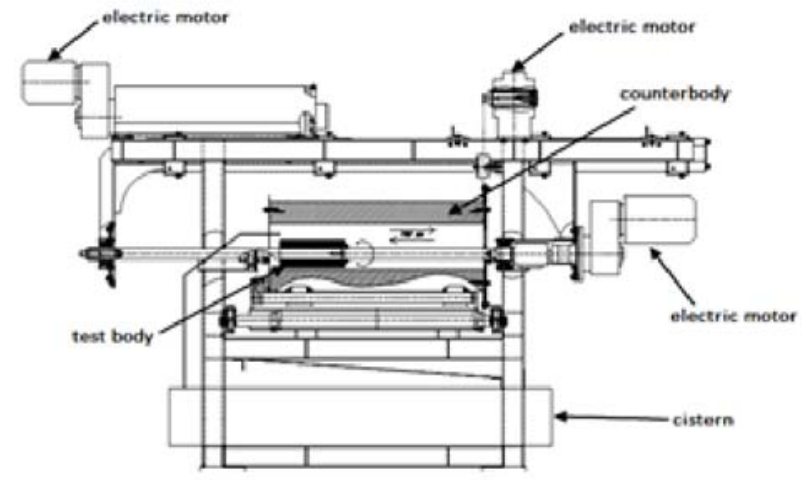

Fig. 2. Layout of the test bench (to test wear resistance of coatings).

The following conditions are necessary to test wear resistance of coatings: pressing force of the test body to the counter body is $100 \mathrm{kgf}$; the rotation speed of the test body is $100 \mathrm{rpm}$; the speed of movement of the test body along the axis of the shaft is $3 \mathrm{~m} / \mathrm{h}$; counter body rotation speed is $0.1 \mathrm{rpm}$; flushing liquid is water.

\section{Results and Discussion}

Figure 3 and table 2 show the microstructure and microhardness values of the alloy with different coatings. The structure of the alloy consists of grains of an $\alpha$-solid solution and inclusions of intermetallic compounds. In the quenched and aged state, the anisotropy of the deformed alloy is manifested to a greater extent. The intermetallic phases are more evenly distributed over the thickness and length of the annealed pipe billets. Accordingly, the microhardness of the annealed alloy with $G$ coatings is significantly lower than that of the hardened and aged alloy with $\mathrm{P}$ and $\mathrm{K}$ coatings.

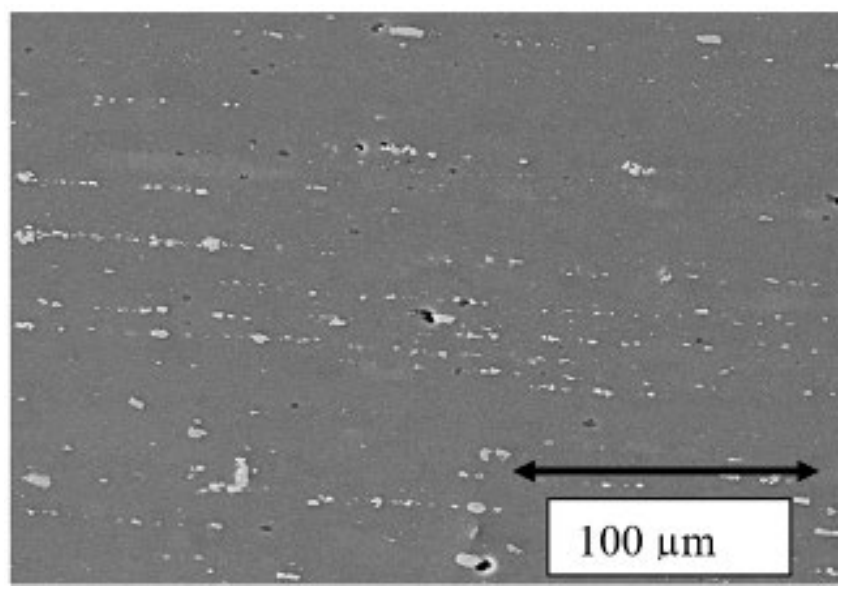

(a) 


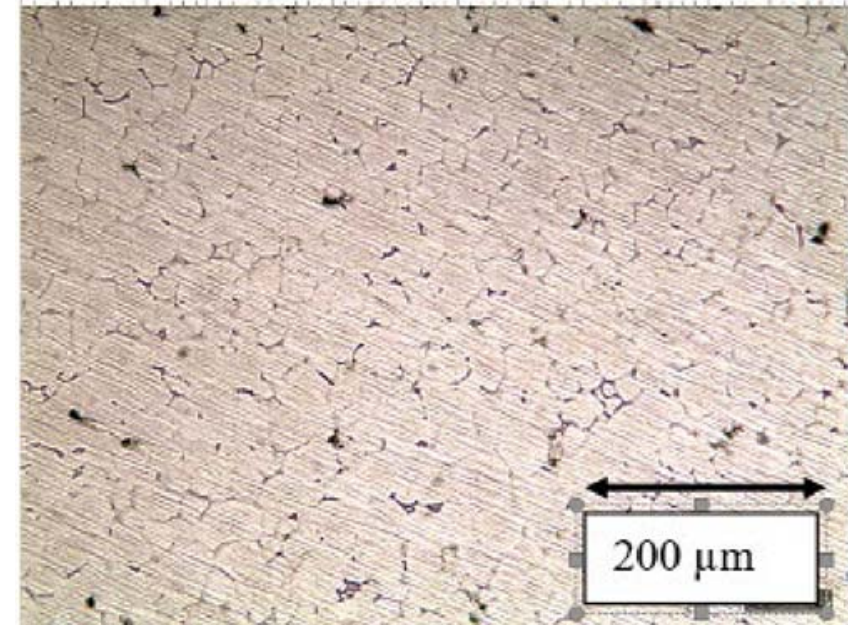

(b)

Fig. 3. Microstructure of D 16 alloy after quenching and natural aging with coating $P(a)$ and after annealing with coating G (b): longitudinal (a) and transverse (b) sections.

Table 2. Microhardness of aluminum D 16 alloy samples used for deposition various coatings.

\begin{tabular}{|c|c|}
\hline Coating & Microhardness of HV, Pa \\
\hline P 1 & $1400-1550$ \\
\hline P 3 & $1350-1450$ \\
\hline K 1 & $1350-1500$ \\
\hline K 2 & $1400-1550$ \\
\hline K 3 & $1400-1500$ \\
\hline G 1 & $750-850$ \\
\hline G 2 & $730-780$ \\
\hline G 4 & $710-770$ \\
\hline
\end{tabular}

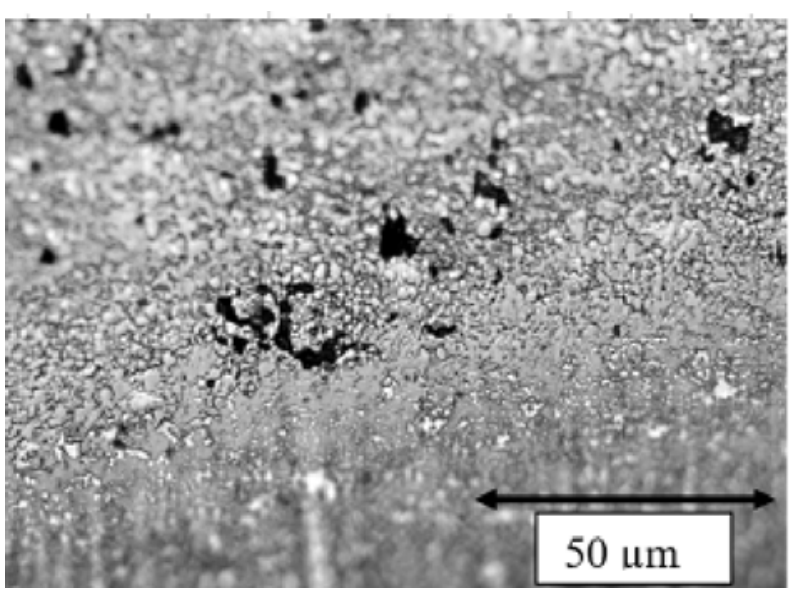

(a)

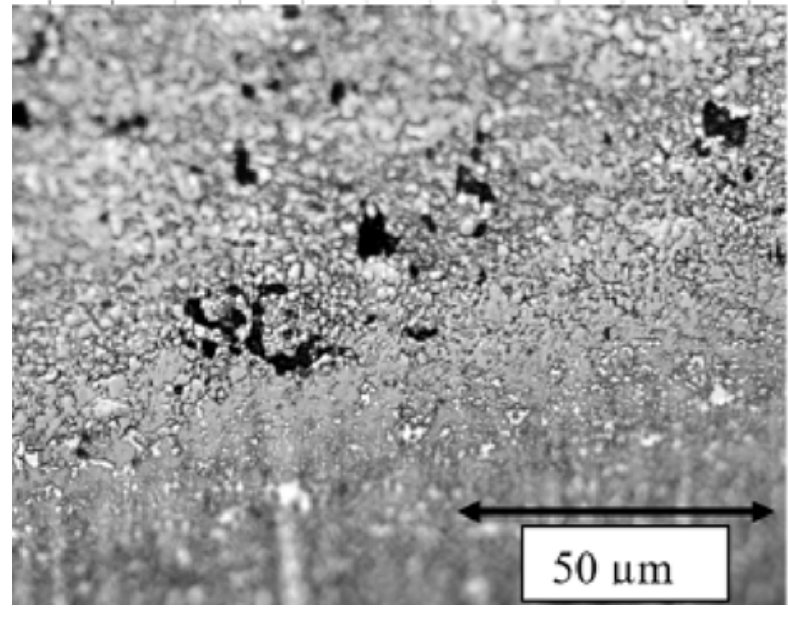

(b)

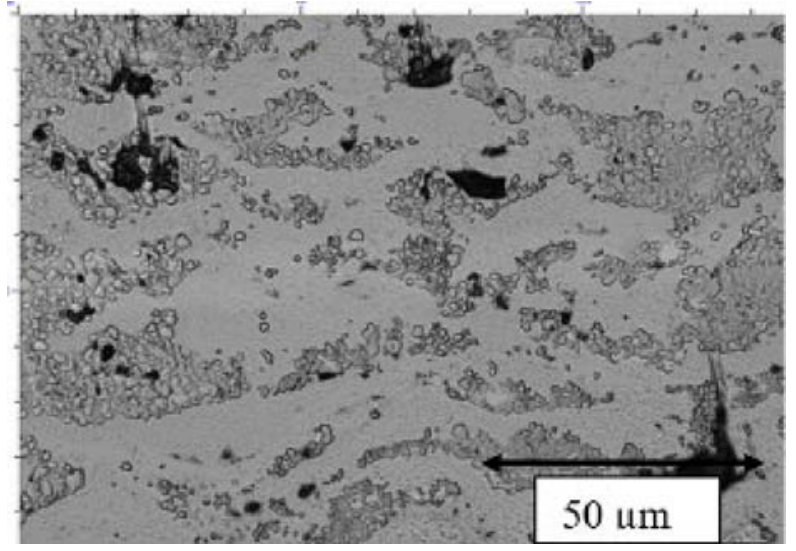

(c)

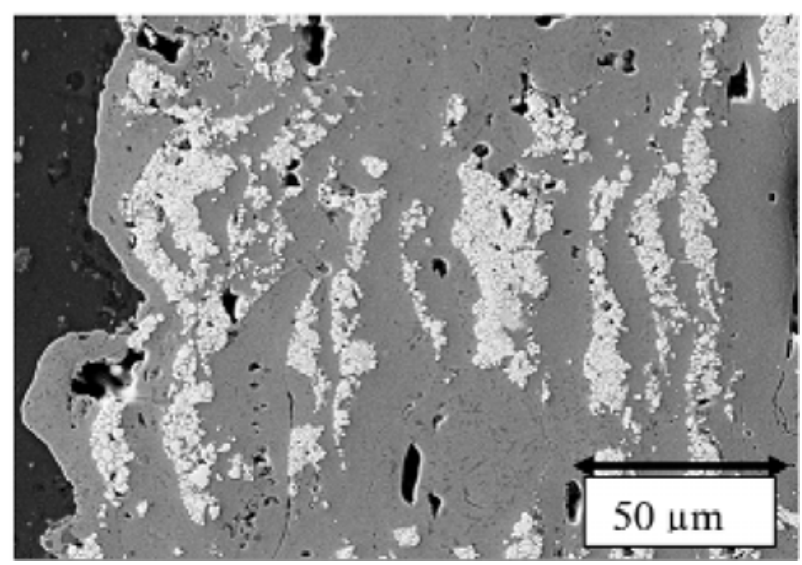

(d)

Fig. 4. Microstructure of coatings $P 1(a, b)$ and $P 3(c, d)$ : optical microscope $(a, c)$; electron microscope $(b, d)$.

Figure 4 presents the microstructure of $\mathrm{P} 1$ and $\mathrm{P}$ 3 coatings. The microstructure of $\mathrm{P} 1$ coating with a thickness of $120 \mu \mathrm{m}$ is homogeneous over the entire surface of the sample with a small number of pores evenly distributed over the cross section and length of the coating; the amount of porosity is $1.94 \%$. Analysis of the chemical composition of the $\mathrm{P} 1$ coating showed that it entirely consists of tungsten carbide, which is confirmed by its high microhardness of $11300 \mathrm{HV}$. The 
microstructure of $\mathrm{P} 3$ coating contains two structural components: $\sim 50$ vol. $\%$ of tungsten carbide with a hardness of $12000 \mathrm{HV}$ and $\sim 50$ vol. \% of a binder of the $\mathrm{Ni}-\mathrm{Cr}-\mathrm{Si}$ system with a hardness of $8700 \mathrm{HV}$. Porosity of this coating is higher in comparison with $\mathrm{P} 1$ and amounts to $3.25 \%$, and its thickness is $160 \mu \mathrm{m}$.

The microstructure of coatings $\mathrm{K} 1,2$, and 3 is shown in Fig. 5. The structure of $\mathrm{K} 1$ coating is uniform, porosity is $0.038 \%$, thickness is $80 \mu \mathrm{m}$; the coating consists entirely of tungsten carbide with a hardness of $12300 \mathrm{HV}$. The structure of the K 2 coating with a thickness of $160 \mu \mathrm{m}$ consists of two components: $\sim 53$ vol. \% tungsten carbide with a hardness of $12000 \mathrm{HV}$ and $\sim 47$ vol. $\%$ of a Ni-Cr-Si system binder with a hardness of $8700 \mathrm{HV}$. Porosity of the coating increases from $0.032 \%$ at the center to $0.21 \%$ on the surface. The structure of K 3 coating consists mainly of a mixture of the Ni-Cr-Si system with a hardness of $6300 \mathrm{HV}$ and a small amount $(\sim 3.98$ vol. $\%)$ of $\mathrm{Al} 2 \mathrm{O} 3$ oxide, which forms conglomerates. Porosity of K 3 coating is $4.45 \%$, and its thickness is $170 \mu \mathrm{m}$.

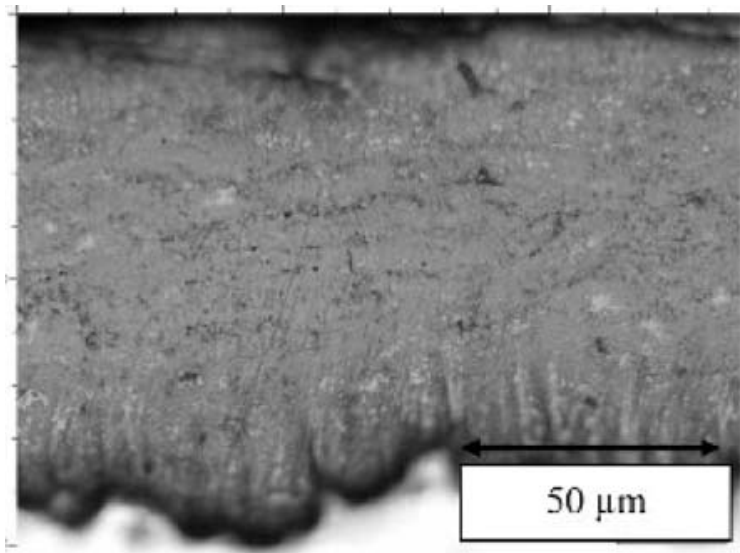

(a)

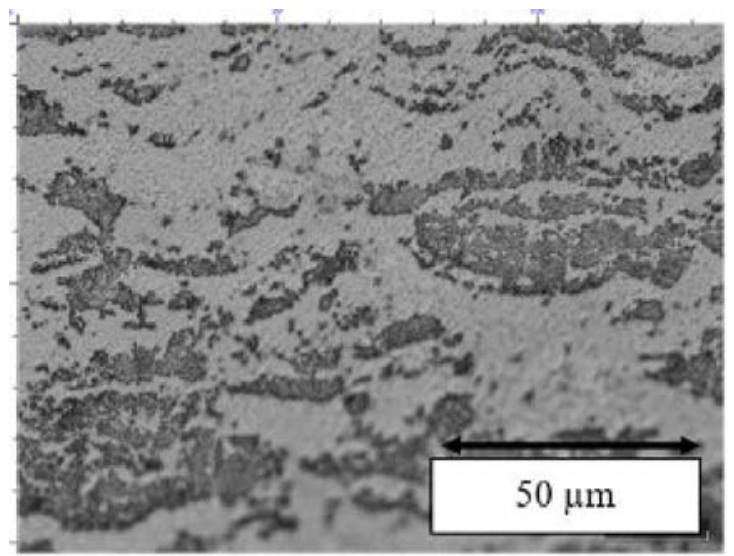

(b)

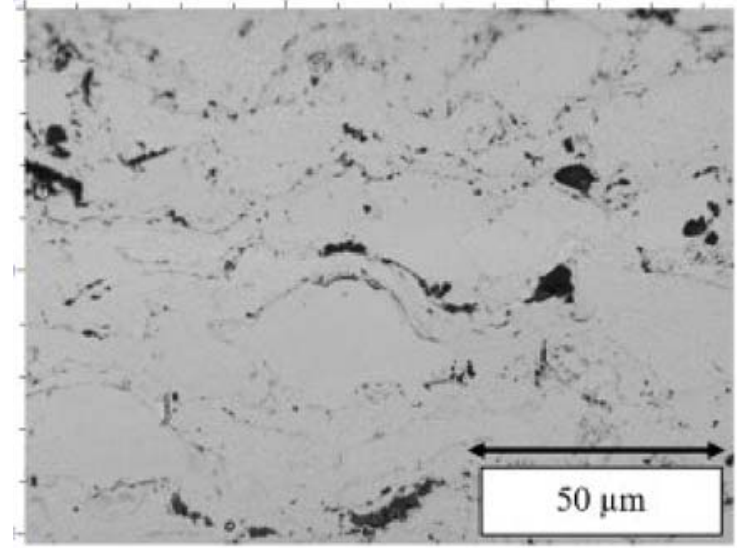

(c)

Fig. 5. Microstructure of coatings K 1 (a), K 2 (b), K 3 (c).

The microstructure of coatings $\mathrm{G} 1,2$, and 4 is shown in Fig. 6. The structure of the $\mathrm{G} 1$ coating consists of two layers: the outer one - (up to 30 microns thick) consists of tungsten carbide with a hardness of $11600 \mathrm{HV}$ and the inner one consists of a mixture of the Ni-Cr-Mo system with a hardness of $5500 \mathrm{HV}$. The average porosity of the coating is $0.54 \%$ and is concentrated mainly in the inner layer. Total thickness of the coating is 120 microns, and thickness of the outer layer is 25-30 microns, and its continuity is low - there are areas without coating. The microstructure of $\mathrm{G} 2$ coating with a thickness of $140 \mu \mathrm{m}$ is homogeneous and consists of a mixture of $\mathrm{Fe}-\mathrm{Cr}-\mathrm{Ni}$ composition with a microhardness of $7900 \mathrm{HV}$ and a porosity of $0.083 \%$. The microstructure of G 4 coating with a thickness of $326 \mu \mathrm{m}$ is also relatively homogeneous and consists of tungsten carbide with a hardness of $12,900 \mathrm{HV}$, its porosity is $0.76 \%$.

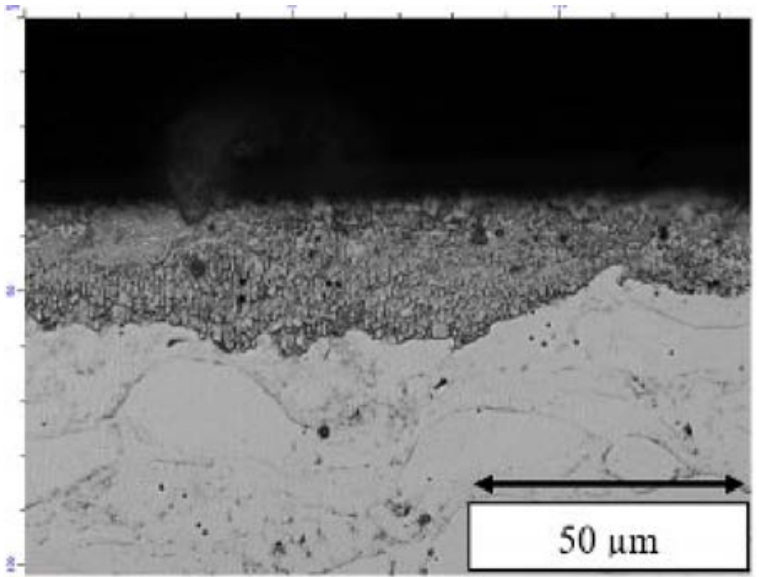

(a) 


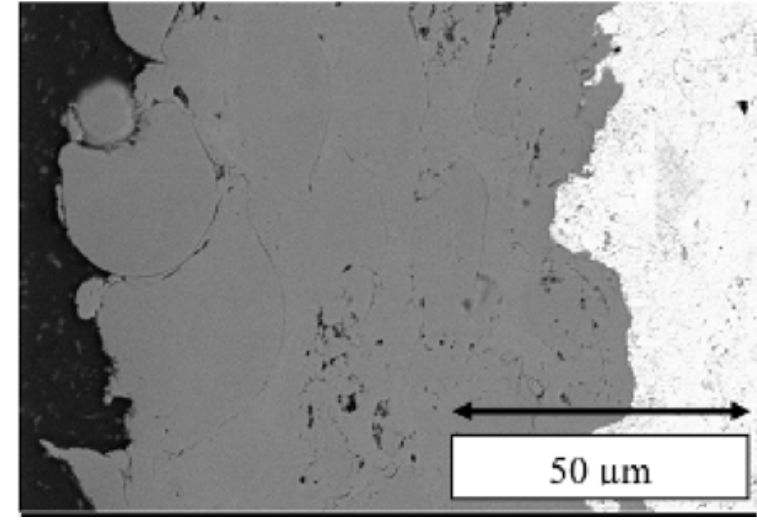

(b)

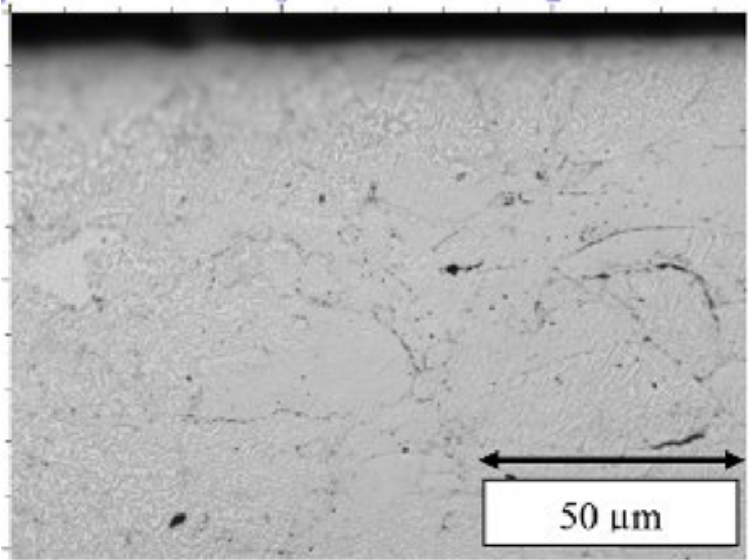

(c)

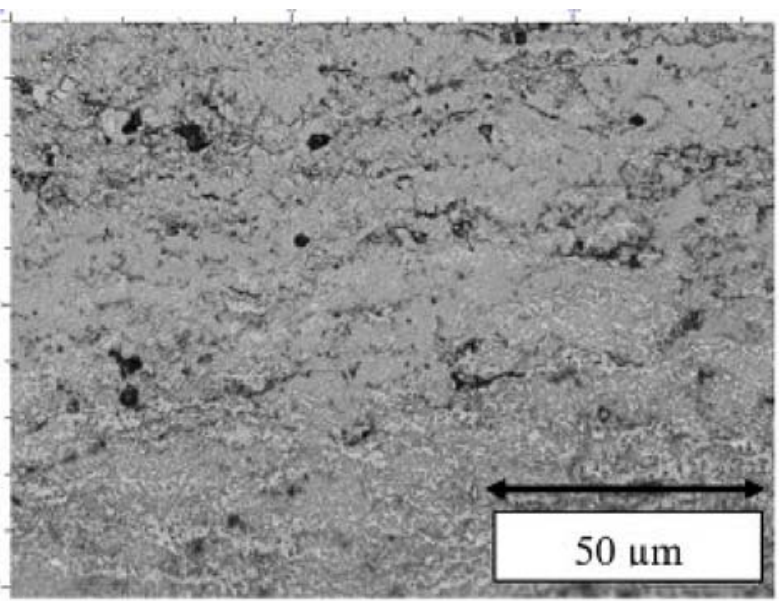

(d)

Fig. 6. Microstructure of $\mathrm{G} 1$ (a, b), G 2 (c), G 4 (d) coatings: optical microscope (a, c, d); electron microscope (b).

The results of metallographic analysis of coatings are summarized in Table 3.

Table 3. Characteristics of the investigated coatings.

\begin{tabular}{|c|c|c|c|c|}
\hline Coating & $\begin{array}{c}\text { Coating } \\
\text { composition }\end{array}$ & $\begin{array}{c}\text { Structural } \\
\text { homogeneity }\end{array}$ & $\begin{array}{c}\text { Porosity, } \\
\mathbf{\%}\end{array}$ & $\begin{array}{c}\text { Microhardness, } \\
\text { of HV, Pa }\end{array}$ \\
\hline P 1 & WC & + & 1.94 & 11300 \\
\hline P 3 & $\begin{array}{c}\text { WC } \\
\text { Ni-Cr-Si }\end{array}$ & - & 3.25 & 12000 \\
\hline K 1 & WC & + & 0.04 & 12300 \\
\hline K 2 & $\begin{array}{c}\text { WC } \\
\text { Ni-Cr-Si }\end{array}$ & - & 0.03 & $\begin{array}{c}12000 \\
8700\end{array}$ \\
\hline
\end{tabular}

\begin{tabular}{|c|c|c|c|c|}
\hline K 3 & Ni-Cr-Si & - & 4.45 & 6300 \\
\hline G 1 & $\begin{array}{c}\text { WC } \\
\text { Ni-Cr-Ni-Mo }\end{array}$ & + & 0.54 & $\begin{array}{c}11600 \\
5500\end{array}$ \\
\hline G 2 & Fe-Cr-Ni & + & 0.08 & 7900 \\
\hline G 4 & WC & + & 0.76 & 12900 \\
\hline
\end{tabular}

Thus, $\mathrm{K} 1$ coating is the best in the context of studied characteristics. P 1, K 2, G 2 and G 4 coatings also have satisfactory characteristics. G 1coating is not promising for practical use due to its low continuity of the outer (hard) layer and relatively low hardness of the inner layer.

Figure 7 presents the results of measuring D16 alloy electrode potentials without and with different coatings. Values of electrochemical potential for all D16 alloys without coating are $580-612 \mathrm{mV}$, which is more negative by more than $100 \mathrm{mV}$ than the potentials of D16 alloy with coatings. Therefore, at the point of contact of the coating with the aluminum alloy, the aluminum alloy will undergo corrosive dissolution. Therefore, when determining the rate of contact corrosion of samples by weight loss, only the surface area of an aluminum sample not covered by a wear-resistant coating was taken into account.

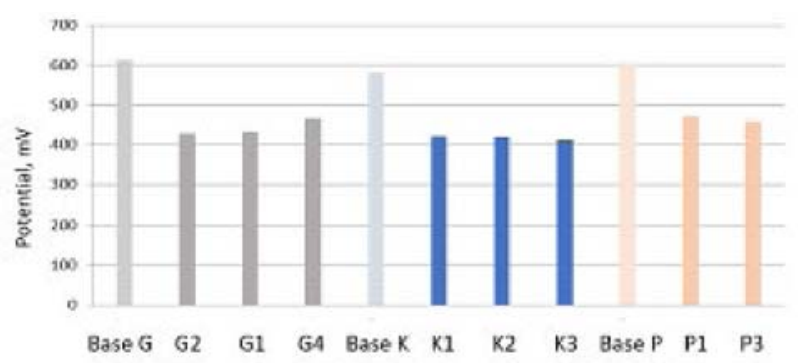

Fig. 7. Values of electrode potentials of D16 aluminum alloy.

The results of tests on contact corrosion of D 16 alloy without coating and with different coatings are shown in Fig. 8. It can be seen that wear-resistant coatings at the point of contact with the base metal somewhat increase the corrosion rate of D 16 alloy from $0.06 \mathrm{~mm} /$ year to 0.08-0.12 mm / year. Consequently, after 8-12 years of operation a groove-like deepening of up to $1 \mathrm{~mm}$ in depth can be formed at the place of contact with the coating on an aluminum alloy

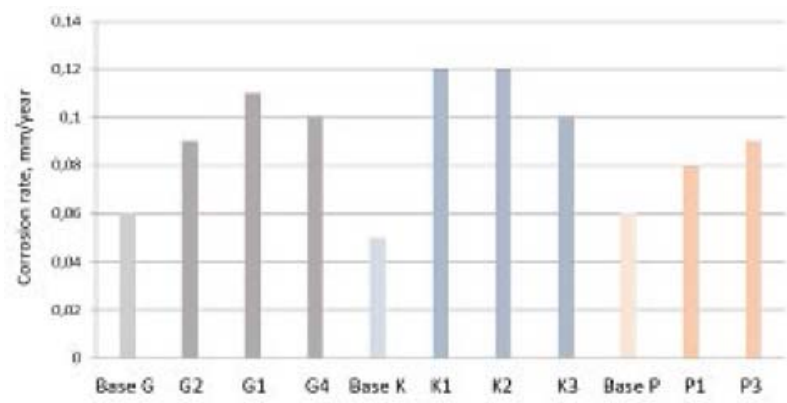

Fig. 8. Corrosion rate of D 16 aluminum alloy (table 1) without coating and with different coatings.

Table 4 shows the results of tests on three-point bending of D 16 alloy with coatings. The maximum deflection before the formation of a crack in the coating 
was recorded on the samples of the alloy with coatings $G$ 1 and G 2 . The calculated maximum stresses in the zone of their destruction are $1040 \mathrm{MPa}$. The values of the fracture stress of $P 1, G 4, K 1$ and $K 3$ coatings have an average level, and $\mathrm{P} 3$ and $\mathrm{K} 2$ coatings are the lowest.

Table 4. Three-point bending test results for alloy D16 with various coatings.

\begin{tabular}{|c|c|}
\hline Coating & $\begin{array}{c}\text { Maximum stresses in the area of } \\
\text { destruction of the coating, MPa }\end{array}$ \\
\hline P1 & 1000 \\
\hline P3 & 800 \\
\hline G1 & 1040 \\
\hline G2 & 1040 \\
\hline G4 & 1000 \\
\hline K1 & 1020 \\
\hline K2 & 980 \\
\hline K3 & 1020 \\
\hline
\end{tabular}

The results of wear tests of D 16 alloy with various coatings are summarized in Table 5, the appearance of the samples after testing is shown in Fig. 9. The most wear-resistant coatings are P $1, \mathrm{~K} 1$ and $\mathrm{G} 4$.

Table 5. Results of tests on wear resistance of D 16 alloy with various coatings

\begin{tabular}{|c|c|c|c|}
\hline Coating & Marking & $\begin{array}{l}\text { A loss } \\
\text { mass, g }\end{array}$ & $\begin{array}{c}\text { Test } \\
\text { duration, } \\
\text { min }\end{array}$ \\
\hline \multirow{3}{*}{$\mathrm{P} 1$} & P1.1 & 2,4 & 240 \\
\hline & $\mathrm{P} 1.2$ & 0 & 480 \\
\hline & P1.3 & 0,3 & 480 \\
\hline \multirow{3}{*}{ P3 } & P3.1 & 6,2 & 120 \\
\hline & P3.2 & 8,7 & 480 \\
\hline & P3.3 & 6,9 & 480 \\
\hline \multirow{2}{*}{ G1 } & G1.1 & 0,2 & 30 \\
\hline & G1.2 & 0,7 & 30 \\
\hline \multirow{2}{*}{ G2 } & G2.1 & 12,5 & 30 \\
\hline & $\mathrm{G} 2.2$ & 19,5 & 30 \\
\hline \multirow{3}{*}{ G4 } & G4.1 & 0 & 480 \\
\hline & G4.2 & 0 & 480 \\
\hline & G4.3 & 0 & 480 \\
\hline \multirow{3}{*}{$\mathrm{K} 1$} & K1.1 & 0,1 & 480 \\
\hline & $\mathrm{K} 1.2$ & 0 & 480 \\
\hline & $\mathrm{K} 1.3$ & 0 & 480 \\
\hline \multirow{3}{*}{$\mathrm{K} 2$} & K2.1 & 31,5 & 30 \\
\hline & $\mathrm{K} 2.2$ & 10,6 & 30 \\
\hline & $\mathrm{K} 2.3$ & 9,8 & 30 \\
\hline \multirow{3}{*}{$\mathrm{K} 3$} & K3.1 & 2,2 & 480 \\
\hline & K3.2 & 2,2 & 480 \\
\hline & K3.3 & 2,2 & 480 \\
\hline
\end{tabular}

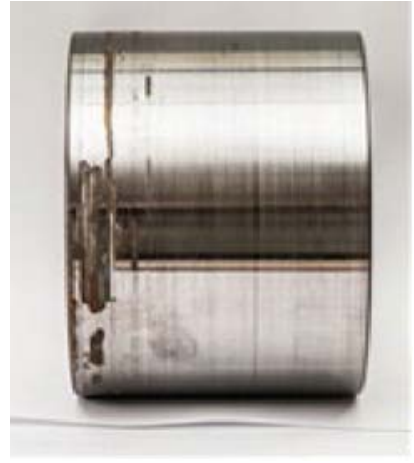

P1.1

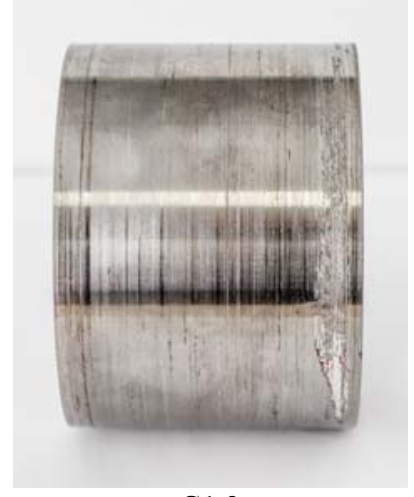

G1.2

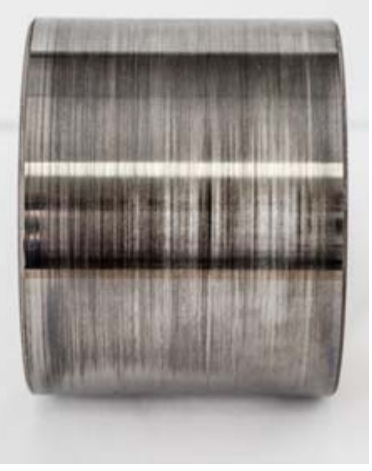

G4.1

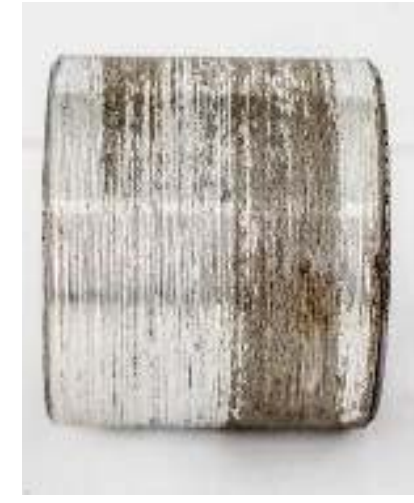

K2.1

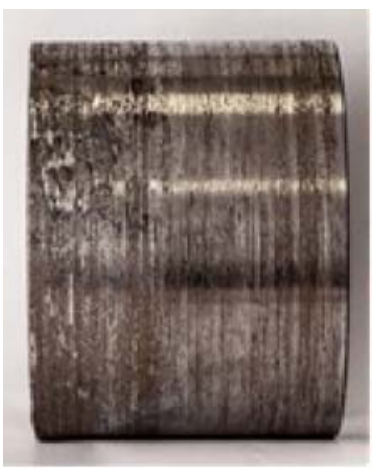

P3.1

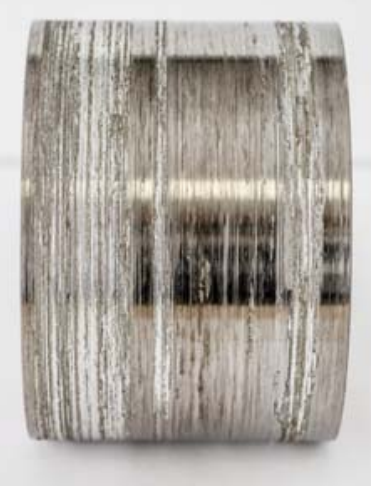

G2.2
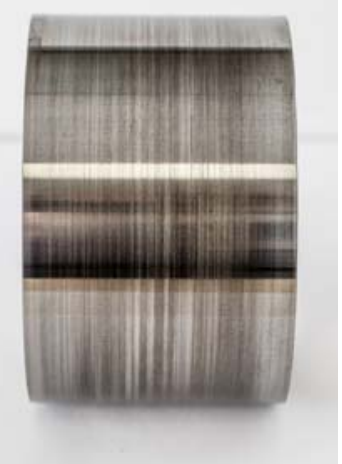

K1.1

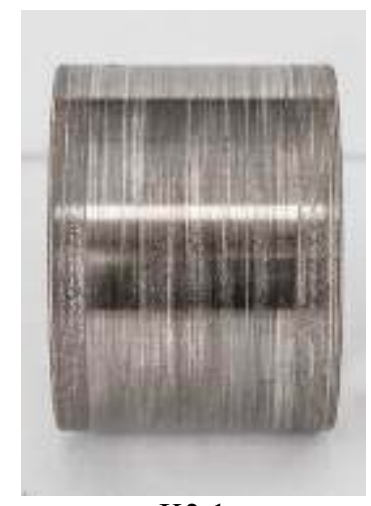

K3.1
Fig.9. Appearance of samples of D 16 alloy with various coatings after tests on wear resistance. Sample marking is presented according to Table 5 .

We used MarSurf1 profilometer to assess roughness in order to compare worn surfaces of the coatings under study. The results of roughness measurements are given in Table. 6 . 
The smallest value of roughness $(\mathrm{Ra})$ has the samples of the alloy coated with $\mathrm{G} 4$. On the surface of the alloy with the coatings $P 1$ and $\mathrm{K} 1$, after tests, zones with a sufficiently significant local wear of up to $20 \mu \mathrm{m}$ were found.

Table 6. Evaluation of the surface roughness of coatings on alloy D16 after wear tests.

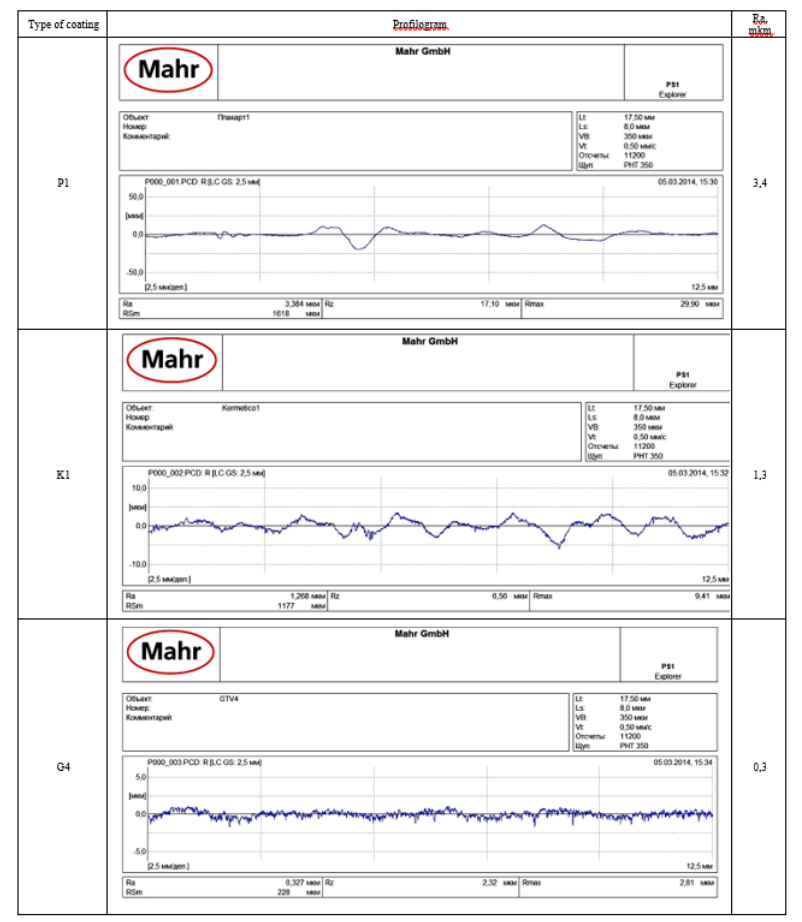

In general, summarizing the results of a comprehensive study of coatings on the D16 aluminum alloy, one can rank their performance characteristics on a ten-point scale (Table 7).

Table 7. Generalized results of the study of the performance characteristics of the D16 alloy with various coatings.

\begin{tabular}{|c|c|c|c|c|}
\hline Coating & $\begin{array}{c}\text { Corrosion } \\
\text { resistance }\end{array}$ & $\begin{array}{c}\text { Mechanical } \\
\text { properties }\end{array}$ & $\begin{array}{c}\text { Wear } \\
\text { resistance }\end{array}$ & Result \\
\hline P1 & 9 & 9 & 8 & 26 \\
\hline P3 & 9 & 8 & 5 & 22 \\
\hline G1 & 9 & 10 & 1 & 20 \\
\hline G2 & 9 & 10 & 1 & 20 \\
\hline G4 & 9 & 9 & 10 & 28 \\
\hline K1 & 9 & 9 & 9 & 27 \\
\hline K2 & 9 & 8 & 1 & 18 \\
\hline K3 & 9 & 9 & 7 & 25 \\
\hline
\end{tabular}

\section{Conclusion}

Evaluation of the performance properties of D 16 alloy with various coatings under conditions corresponding to the operation of drill pipes allows us to conclude the following. All investigated coatings increase the properties of aluminum drill pipes. However, if all coatings are comparable in terms of their effect on the corrosion and mechanical properties of the alloy, then their effect on wear resistance is significantly different and depends on the composition and structure of the coating. The best set of service properties of D 16 alloy for the operating conditions of drill pipes in oil production is provided by the G4 (WC) coating, which increases the wear resistance of the material to the greatest extent. Coating $\mathrm{K} 2(\mathrm{WC}+\mathrm{Ni}-\mathrm{Cr}-\mathrm{Si})$ has the lowest rates.

\section{References}

1. G.M. Fine, G.S. Makarov, Tekhnologiya legkikh splavov. No. 1. P. 16-20, (2002)

2. V.S. Basovich, I.N. Buyanovskiy, I.V. Petunkin, Drilling and oil. No. 6. P. 81-85 9 (2015)

3. M. Tan, L. Gan, Science in China Series E: Technological Sciences, V. 52. No. 3. P. 590 -595, (2009)

4. M.D. Fuks, Y.V. Zelenin, S.Y. Kondratyev, Procurement production in mechanical engineering, No. 2. p. 36-38, (2012)

5. A.I. Shakirova, M.N. Nazarova, R.A. Ismakov, A.R. Khafizov, N.K. Tsenev, Materials for technical devices and structures used in the Arctic: M. FGUP VIAM, p. 1-20, (2015)

6. V.V. Zakharov and V.I. Elagin, T. D. Rostov, M.V. Samarina, Technology of light alloys. No. 4. p. 7-13, (2008)

7. S.S. Kolesov, S.Yu. Kondratyev, V.V. Chizhikov, O. V. Shvetsov, Procurement production in mechanical engineering, No. 4. p. 39-43, (2011)

8. L.J. Hong, P.G. Scaruffi, T.W. Brewster, S.M. Balka, SPE ATCE, 19-22,134949 (2010)

9. C.Yu. Kondratyev, O. V. Shvetsov, Metallurgy and heat treatment of metals. No. 4 (694). p. 24-30, (2013)

10. O.V. Shvetsov, S.Yu. Kondratyev, Tekhnologiya mashinostroeniya, No. 5. p. 31-36, (2012)

11. C.Yu. Kondratyev, O. V. Shvetsov, A.A. Alkhimenko, Scientific and technical bulletin of SPbPU, No. 2 (195). p. 93-99, (2014)

12. O.V. Shvetsov, A.A. Alkhimenko, S.Yu. Kondratyev, Scientific and technical bulletin of SPbPU. No. 3 (202). p. 180-191, (2014)

13. B.A. Kolachev, V.I. Elagin, V.A. Livanov, Metallurgy and heat treatment of non-ferrous metals and alloys, $413 \mathrm{p}$, (1999)

14. I. N. Fridlyander, MiTOM, No. 9. p. 8-11, (2003)

15. V. Gorynin, S. Kondrat'ev, V. Popov, Photonics, No. 3 (21). p. 26-33, (2010)

16. S.Yu. Kondratyev, V.I. Gorynin, V.O. Popov, Welding production, No. 3. p. 11-15, (2011)

17. S.Yu. Kondratyev, Mechanical properties of metals: a tutorial, 128 p. (2011) 